\title{
Slope Morphology and Impacts on Agricultural Productiviy in the Kom Highlands of Cameroon
}

\author{
Hycinth N. Tossam \\ Department of Geography \\ Faculty of Social and Management Sciences \\ University of Buea, P.O. Box 63 \\ Lawrence F. Fombe \\ Department of Geography \\ Faculty of Social and Management Sciences \\ University of Buea, P.O. Box 63
}

\begin{abstract}
Very steep and rugged slopes impact significantly on agricultural processes and patterns as characterized by the Kom highland of the Northwest Region of Cameroon. The study examines the aspects of slope morphology that influence agricultural production and how the inhabitations react to slope elements (gradient, soil, climate and altitude) in an effort to increase agricultural productivity and improve on their livelihoods. Primary data was collected through the use of questionnaires, interviews, field observations focus group discussions and measurements. Secondary data on the agro-ecological zones of the study area and soil characteristics was obtained from the Divisional Delegation of Agriculture for Boyo. Information on the slope characteristics, the slope gradients and altitudinal classification was obtained from the topographic maps of the study area and GPS coordinates. The main findings indicate that agricultural practices in the Kom highlands significantly depend on slope morphology which has obliged the mountain dwellers to adopt coping mechanisms such as contour ploughing, mixed cropping and mixed farming in order to minimize the impacts of slope configuration on their farming activities.
\end{abstract}

Key Words: Boyo, Contour Ploughing, Mixed Cropping, Slope Gradient, Soil Creep.

\section{INTRODUCTION}

Slope gradient naturally controls the pattern of agricultural productivity in developing regions through its role in determining the type of agriculture, yields and methods of cultivation that is practiced in any area. The steeper the gradient, the greater the risk of soil erosion since the soils are thinner on steep than on gentle slopes. On steep slopes it is more difficult and dangerous to use heavy machinery as in modern agriculture. It has been estimated that efficient cultivation is impossible on gradients of more than 110 and arable cultivation is impossible on 180 slopes (Hammond, 1985). Table 1 shows the correlation between slope gradient and the ease of agricultural land use

Steep slopes also facilitate the rate of runoff and soil creep. Soil creep and other forms of mass wasting are also accelerated and consequently all the processes of soil formation are retarded. It is for this reason that soils on steep slopes are either very thin or acidic. The upper parts of high mountains such as the Andes, Rockies, Himalayas, Alps, Atlas and Kilimanjaro are ruled out for any meaningful agriculture (Nkemasong and Neba, 2009). 
Table 1 correlation between slope gradient and the ease of agricultural land use in the UK

\begin{tabular}{|c|c|l|l|}
\hline \multicolumn{2}{|l|}{ Gradient } & \multirow{2}{*}{ Description } & \multirow{2}{*}{ Comments } \\
\cline { 1 - 2 } Degree & Ratio & Gently sloping & Farming operations easily carried out \\
\hline 3 & 1 in 20 & moderate & No serious obstacle to farming easily cultivated \\
\hline 6 & 1 in 10 & Fairly steep & Limit for ground plough and cut annually \\
\hline 11 & 1 in 5 & Steep & $\begin{array}{l}\text { Maximum slop under cultivation ploughing difficult and } \\
\text { hazardous. generally permanent grass }\end{array}$ \\
\hline 25 & $\operatorname{lin} 3$ & Steep & Too steep for cultivation maybe forested if soil is present \\
\hline
\end{tabular}

Source: D.R Macgregor, some observations on the Geographical significance of slopes, Geography, Volume 42, cited in Knowles and Wareing, 1981:125

In many parts of the world, especially on the slopes of the Himalayas in South East Asia, the slopes of the Mexican Plateau, and the Mandara Mountain area of Cameroon, complex systems of terraces have been developed so as to permit an extension of cultivation into areas of steep slopes (Lambi, 2001). Other methods of cultivating steep slopes are through the construction of walls or fences and contour ploughing as in the Western Highlands of Cameroon and most particularly in the Kom Highlands.

Since the cultivation of steep slopes is not easy, most of these slopes are devoted to activities like grazing, perennial bush cropping, timber and tea plantations (Nkemasong and Neba, 2009).This pattern of hills slope agriculture is common in the Western Highlands of Cameroon including the Kom Highlands where crop production is greatly influenced by the slope configuration. Soils eroded from the steep slopes accumulate on the gentle slopes and valleys thereby making the valleys more suitable for crop cultivation than the highlands. For instance the existence of the numerous peasant and capitalist plantations along the coastal lowlands of and the Southern Low Plateau of Cameroon is indicative that the gentle slopes favour the establishment of these plantations. Some crops grow only in lowlands where temperatures are relatively higher than in the highlands. Such crops include oil palm, rubber and cocoa. On the contrary, coffee and tea thrive in high altitude areas. Most productive agricultural systems are developed on lowlands. This is the case of the highly developed intensive farms of Western Europe and the North Sea Plain (Nkemasong and Neba, 2009).

Generally, since the steeper gradients render arable cultivation difficult, farming tends to prevail on flat or gentle and undulating ground and pastoral farming on uplands. Mid-altitude regions situated on slopes of gradients above 300 are generally densely populated with population densities of over 35inhabitants per kilometers square. Kips, et al. (1987) noted that these highland slopes suffer from severe erosional hazards that lower their agricultural potential so that they are not capable of sustained cultivation and cattle breeding. The low altitude areas found on altitudes of less than $900 \mathrm{~m}$ above sea level are generally more suitable for the cultivation of a variety of crops given that soils eroded from the steep slopes accumulate in such areas which also portray relatively warmer climatic conditions. The need for farmland by the teeming montane population has forced it to extend cultivation into water catchments and accelerated biodiversity degradation. Competition for land between farmers and graziers has also generated several farmer-grazier conflicts. Furthermore, the type and variety of crops grown on very steep slopes equally reduce. This is because very few crop types 
can adapt to soils at gradients above 450.Fogwe\&Tchotsoua (2010), noted that the Kom highlands have very steep slopes with the modal gradients being over $30 \%$.Settlements such as Belo, Njinikom, Ibal-Oku and Fundong are situated on gentler gradients where perennial cropping is carried out. The marginal steep slopes of these areas are rather used for shifting cultivation and annual cropping as well as livestock grazing.

Slope types can be categorised based on their degree of steepness. Ndenecho (2007) identified four main slope categories in the Bamenda highlands. These are the rolling, moderately steep, steep and very steep slopes. The rolling slopes have gradients of between $8 \%$ and $16 \%$. Slopes that correspond to this category in the Kom-Highlands are found in areas like Baicham, Mbueni and Mbonkissu .Such slopes have probably developed on sedimentary rock basins. Sedimentary slopes Sedimentary slopes are generally moderate or fairly steep ((Khanchoul \& Altschul, 2008) and contain deeply weathered soils which are suitable for the cultivation of crops given that these are basins of material accumulation from the steep and moderate slopes. Next are the moderately steep slopes with gradients between $16 \%$ and 30\%.They are located at the foothills and some on the high lava plateau. In the Kom highlands, such slopes occur in localities like Belo, Njinikom and Fundong. The third category are the steep slopes between $30 \%$ and $50 \%$ found in mountainous granites and volcanic peaks composed of trachy rhyolites. In the Kom-Highlands localities with such slope gradients are Tumuku, Muloin and Abuh. The fourth category are the very steep slopes of more than $50 \%$, found on escarpments. This type of slope occurs on the Mbingo-Baingo escarpment.

Agriculture in Cameroon rural areas remains a fundamental source of livelihood. Physical factors generally influence the type of agriculture and systems of cultivation either positively or negatively. The Kom highlands illustrate a situation of slope configuration which exercises a significant influence on the type, nature and methods of crops cultivated. The highlands are dominated by a mountainous topography characterized by steep slopes and narrow valleys with highly lateralized soils which are poor in nutrients due to intense leaching. The rapid increase in population and the need to ensure adequate food supply have forced the peasant population to cultivate the marginal and unstable slopes. Based on the 1976 population census of Cameroon, the population of the Kom highlands was estimated at 91,065. Eleven years later, the population had risen to 101,605 and in 2010, the population of the study area was estimated at 107,049 persons (Bureau Centrale des Recensements et des Etudes des Populations-BUCREP, 2010), indicating a yearly increase of $1.3 \%$ on an essentially uncongenial agricultural environment.

While the steep and hilly slopes may not be suitable for some specific food crops, they are, nevertheless suitable for highland crops such as tea and coffee cultivation as well as animal grazing. However, these type of faming does not only require huge capital and a large land surface area, but appropriate adaptation techniques in order to ensure sustainability which are beyond the reach of the vast majority of the peasant population that are barely striving for survival.

This paper therefore aims at examining the implications of the slope morphology on agricultural productivity based on the following specific objectives: Describe the slope characteristics in the study area; Explain variation in crop production as a function of slope morphology; Examine agricultural problems associated with slope morphology; Suggest recommendations that would ensure increase productivity and ensure sustainability in this seemingly harsh topographic environment. 


\section{STUDY AREA AND RESEARCH METHODOLOGY}

The Kom highlands are found in Boyo Division of the North West Region of Cameroon (Figure 1). Administratively, it consists of three of four Sub-Divisions that make up Boyo Division (Belo, Njinikom and Fundong). Fundong is the Divisional headquarter of Boyo. The Kom highlands lie between latitudes $6^{\circ} 7^{\prime} / 6^{\circ} 24^{\prime} \mathrm{N}$ and longitudes $10^{\circ} 41^{\prime} / 10^{\circ} 31^{\prime} \mathrm{E}$. It shares territorial limits with Menchum and Bum Sub-Divisions to the West and North West, Noni SubDivision to the North East and Tuba Sub-Division to the South West. The highland has a total surface area of $1,592 \mathrm{~km} 2$ with an estimated population density of 67.2 inhabitants/km2 unevenly distributed across the entire surface area (BUCREP, 2010). This highland is dominantly a hilly terrain with an undulating landscape composed of deep narrow valleys and mountains with altitudes above 3,000metres such as Mount Boyo.

The study entailed field observations where the type of crops cultivated in the study area and the techniques of cultivation were identified. This entailed the collection of GPS coordinates to determine the low, mid and high altitude regions in the study area. Slope gradients were measured at specific points to corroborate with the calculations that made use of topographic maps of the study area. A total of 420 questionnaires were distributed using a stratified random sample in the three Sub-Divisions that make up the study area (Belo, Njinikom and Fundong).These three Sub-divisions which make up the Kom-Highlands were grouped into agro-ecological zones based on statistics provided by the Boyo-Divisional Delegation of Agriculture and GPS data collected for the sampled villages in the study area (Table2). The questionnaires were used to obtain information on crop types cultivated as well as farmers' opinions on crop yields at different altitudes. The sample size was calculated based on the following formula:

$$
\mathrm{N}=\frac{n z^{2} p(1-p)}{d^{2}(n-1)+z P(1-p)}
$$

Where $\mathrm{N}=$ total population, $\mathrm{Z}=$ value corresponding to the confidence level, $\mathrm{d}=$ absolute precision, $\mathrm{P}=$ expected proportion in the population

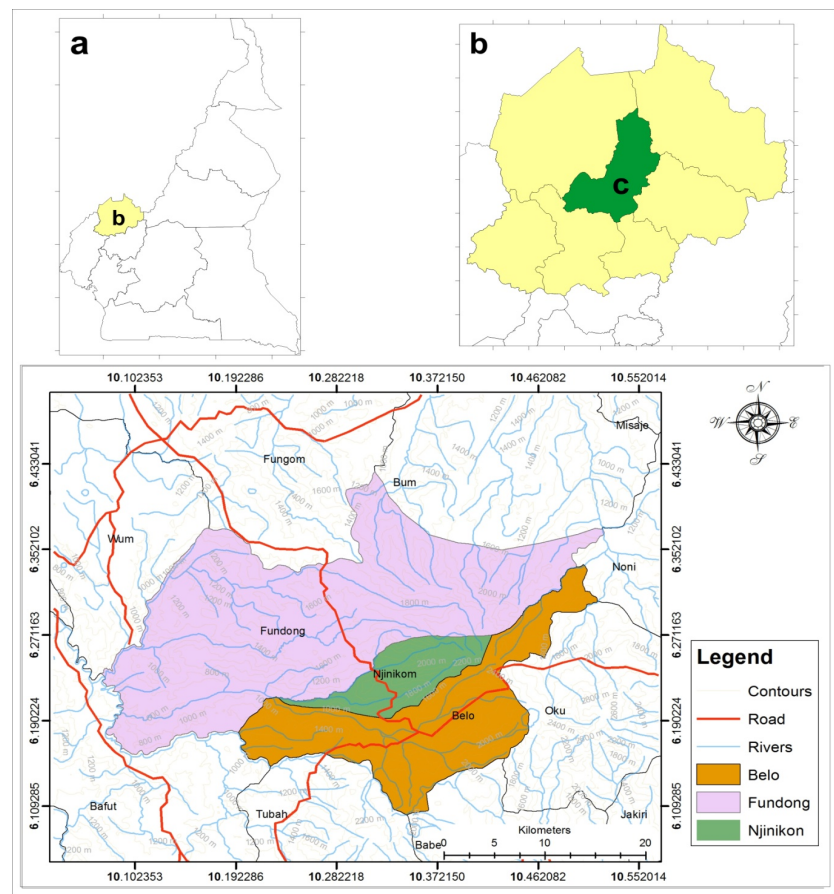

Figure1, Location of the study area (c) in the Northwest Region (b) of Cameroon (a). Source: Derived from the new administrative map of Cameroon. 
Based on the above sample size estimation, the study area was segmented into 9zones with three zones of low altitude (Baicham, Mbueni and Mbonkisu), three of mid-altitude (Belo, Njinikom and Fundong) and the last three of high altitude located on steep gradients (Tumuku,Muloin and Abuh).

Table 2: Agro-Ecological Zones in the Kom Highlands

\begin{tabular}{|c|c|c|c|c|c|}
\hline $\begin{array}{c}\text { Agro- ecological } \\
\text { zones }\end{array}$ & Locality & $\begin{array}{l}\text { Number of } \\
\text { Questionnaires }\end{array}$ & Returned & Sub-Division & $\%$ \\
\hline \multirow[t]{3}{*}{$<900 \mathrm{M}$} & Baicham & 47 & 36 & Belo & 76.5 \\
\hline & Mbueni & 47 & 41 & Njinikom & 87.2 \\
\hline & Mbonkisu & 47 & 37 & Fundong & 82.9 \\
\hline \multirow[t]{3}{*}{$901-1500 \mathrm{M}$} & Belo & 47 & 44 & Belo & 93.6 \\
\hline & Njinikom & 47 & 40 & Njinikom & 85.1 \\
\hline & Fundong & 47 & 41 & Fundong & 87.2 \\
\hline \multirow[t]{3}{*}{$>1500 \mathrm{M}$} & Tumuku & 47 & 39 & Belo & 82.9 \\
\hline & Muloin & 47 & 44 & Njinikom & 93 \\
\hline & Abuh & 47 & 42 & Fundong & 89 \\
\hline TOTAL & & 423 & 364 & & 86.05 \\
\hline
\end{tabular}

Source: Divisional Delegation of Agriculture Boyo (2015) and Field work, 2015

Supplementary information on the different measures used by the inhabitants to adapt their cultivation techniques to the nature of the slope was obtained through interviews and focused group discussions with selected male and female farmers of the three altitudinal zones identified. Secondary data on the annual production of crop and livestock farming in the study area for the past five years and soil characteristics of the study area were obtained through the Annual Reports of the Divisional Delegations of Agriculture, Livestock, Fisheries and Animal Industry for Boyo Division. The data obtained from primary and secondary sources were analysed quantitatively and qualitatively.

\section{RESULTS AND DISCUSSIONS}

\section{Slope morphology and characteristics in the Kom highlands}

The Kom highlands consist of undulating mountain ridges and peaks with steep slopes (Figure, $2 \mathrm{a} \& 2 \mathrm{~b}$ ). They extend from the Bambili-Sabga dorsal (southeast) to the Boyo Hills in the west and culminate in Mount Oku (Fogwe \& Tchotsoua, 2010). The steep and undulating slopes represent a big challenge to the peasant population who must develop appropriate technologies in order to ensure adequate food production so as to meet up with the food needs of the increasing population. As the slope morphology varies from gentle, moderate and very steep, so too, do the climatic conditions, such that at high altitudes the soils are not only very thin but also very acidic. Consequently, the rate of humus decomposition becomes very slow and the growing season is lengthened as compared to the more gentle slopes.

The nature and structural characteristics of the bedrock are the major determinants of slope morphology in the region. Geologically, the highlands is formed on volcanic rocks (tertiary basalt and trachyte lavas) though some uplifting of older granite and gneiss basement rocks has also occurred (Gazel, 1958; Furon, 1963).In the Kom highlands, where andesitic basalt occurs, the landscape is deeply dissected with sharp summits and where trachyte rocks occur, mountain slopes are more rounded, steep and vertical. Much of West Africa including the Kom 
highlands are made up of ancient rocks (Fullard and Darby, 1972) which have been subjected to erosion and planation for millions of years. In the Kom highlands of Cameroon, the presence of volcanic activity during the past 100 million years has led to the formation of very steep and undulating slopes. The bed rockswhich consist of ancient granites are characterized by abrupt outbreak of slopeswhich divide the slope into scarp and gentle undulating surfaces.
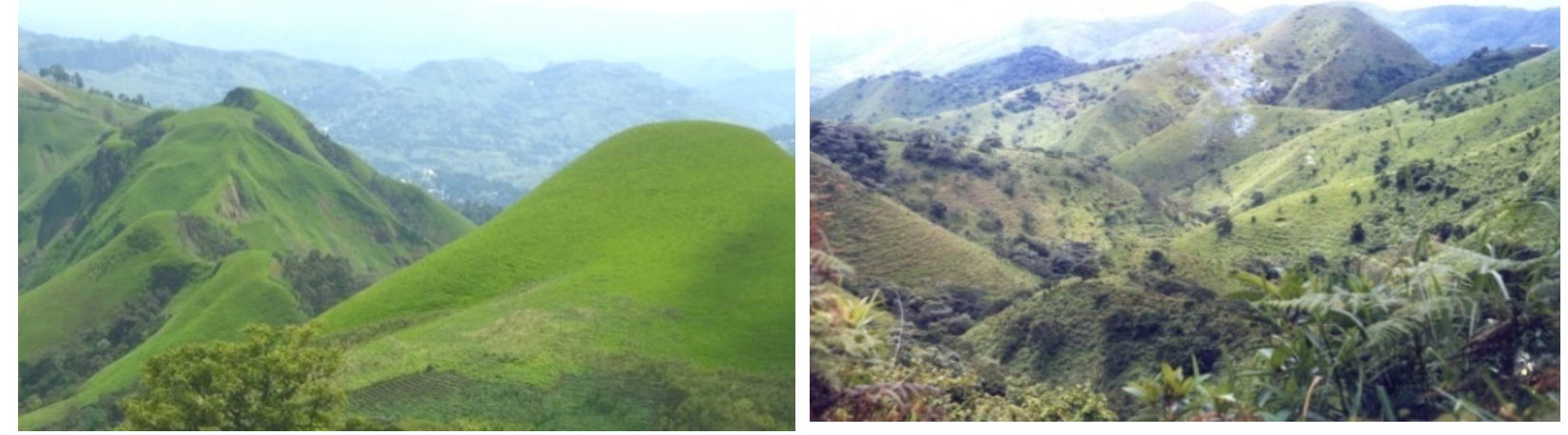

Figure 2 Ridges and steep slopes at Achain .Ridges and steep slopes at Ajung

The scarp surfaces which are steep and irregular rangefrom300to 450.Such slopes are characterised by skeletal soils due the influence of gravity. The Mbingo-Baingo escarpment is a typical example of a slope with steep gradient (Figure 2, a \& b). Soil creep and other forms of mass wasting which frequently occur on such slopes do not only render the soils poor for any form of agriculture but makes all other forms of agricultural land uses difficult to practice. Found in an environment characterised by basement granitic hills and high lava plateau except in the south west where the high granitic hillocks drops to form low-lying plains in Mbeini,Mbonkisu and Baicham, the hilly slopes contain pockets of impoverished soils which are susceptible to erosion and landslides. These pockets do not provide room for any meaningful agriculture. Stone and rubble, of a lateritic bauxite mixture are widespread within the soil profile and on the surface where steep or irregular slopes are found.
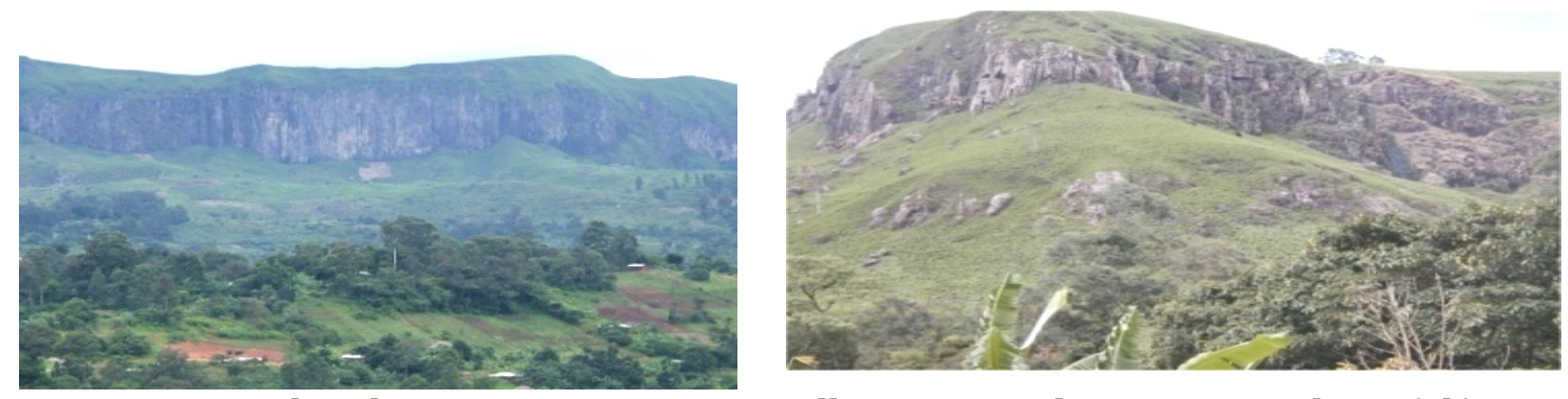

Figure 2a, the Mbingo-Baingo escarpment illustratingRock outcrops in Mbessa(2b)

The Kom highlands is characterized by a huge mountainous landscape which consist of a rugged terrain, steep slopes, extensive escarpments and a dense drainage network that have dissected the mountainous topography producing deep and narrow valleys as illustrated in the digital elevation model (Figure 3).The topography in several locations offers ideal condition for the occurrence of varied forms of mass movements. This is visible on the hilly slopes of villages like Elimighong, Anyajua, Djichami Abuh, the Ngwah hills, Achain and Ajung. 


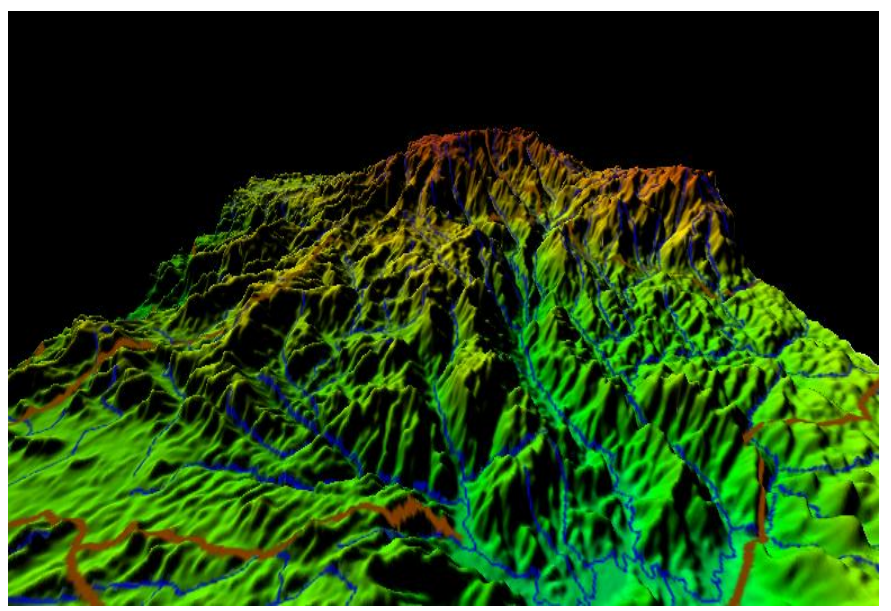

Figure 3 digital elevation models for the Kom-highlands

The relief configuration of the study are varies significantly. The western sections of the study area generally lie within low altitudes, however heights increase sharply towards the west and culminates in the Ndawara Highlands (figure 4a andb).Similarly the south- north orientation of the study area equally show that height increase from the low lying regions such as the Mbueni Plain which are less than $900 \mathrm{~m}$ high to the north in areas like Tumuku,Muloin Abuh where the average altitude in the area generally exceeds $1500 \mathrm{~m}$.

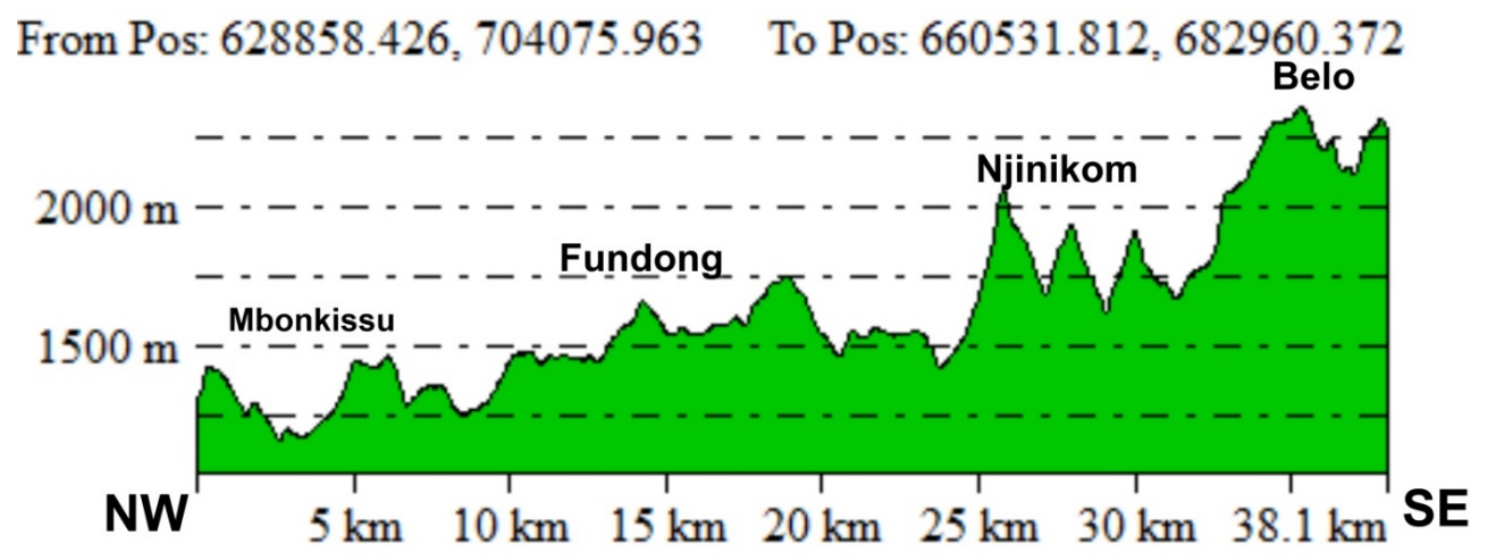

Figure 4a, The Mbonkissu- Belo (northwest - south east orientation of the study area)

From Pos: $645592.412,710206.228$ To Pos: $649483.738,674915.926$

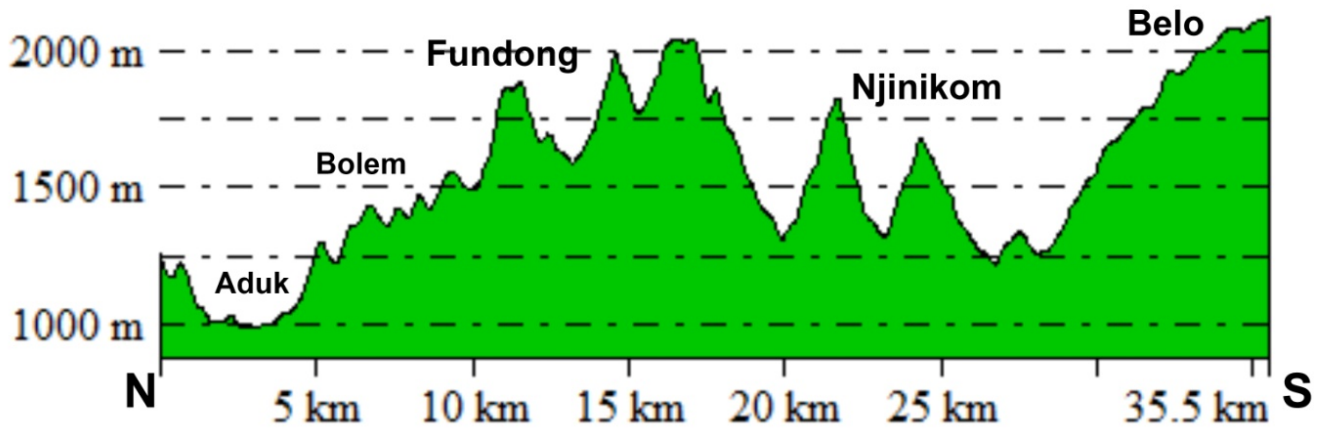

Figure 4b, Aduk-Belo (From north- south orientation)

Source: Derived from the Topographic Map of the study area scale, year 


\section{Variation in crop production as a function of slope morphology}

Agricultural production in terms of crop type and annual yields in the Kom-Highlands vary greatly with slope type. As the nature of the slope varies from gentle, moderate and to steep slopes, so too do crop yields vary. In a study sample of nine villages of the Kom highlands, farm sizes of three hectares for some major crop types cultivated in the study area were considered. Based on this, the crop yields according to the nature of slope for the following slope morphologies were obtained as indicated in Table3.

Table 3, Variation in average crop yields per respondent as a function of slope angle in the Kom highlands

Village location Altitude Slope angle Crop type Estimated farm size (ha) Annual yield (tons)

\begin{tabular}{|c|c|c|c|c|c|}
\hline & \multicolumn{5}{|c|}{ Low altitude } \\
\hline Mbueni & $<900 \mathrm{~m}$ & $5^{\circ}$ & maize & 3 & 10 \\
\hline Baicham & & & beans & 3 & 3 \\
\hline \multirow[t]{2}{*}{ Mbonkisu } & & & coffee & 3 & 2 \\
\hline & \multicolumn{5}{|c|}{ Mid altitude } \\
\hline Belo & $901-1500 \mathrm{~m}$ & $10^{0}$ & maize & 3 & 6 \\
\hline Njinikom & & & beans & 3 & 4 \\
\hline \multirow[t]{2}{*}{ Fundong } & & & coffee & 3 & 5 \\
\hline & \multicolumn{5}{|c|}{ High altitude } \\
\hline Tumuku & $>1500 \mathrm{~m}$ & $15^{0}$ & maize & 3 & 2 \\
\hline Muloin & & & beans & 3 & 4 \\
\hline Abuh & & & coffee & 3 & 7 \\
\hline
\end{tabular}

Source: Field work, 2015

The steep natures of slopes evidently accelerate soil erosion and other forms of mass movements such as soil creep and landslides. This has rendered the soils on such slopes not only skeletal but poor in nutrients. It therefore means that for any successful farming activity on such slopes, there is need to understand the soil characteristics in order to cultivate only crop types that are suitable on such slopes. Unfortunately, this is not the case in the highlands because the inhabitants stick to their traditional technology which is non-adaptable. They cultivate crops haphazardly without regard to the nature of the slope or the soil characteristics. It is for these reasons that even though maize production declines from 10 tons on slopes of 50 to 2 tons on slopes of 150 (Table3), farmers continue to devote energy and extensive patches of the hill slopes for the cultivation of maize.

\section{Agricultural problems associated with slope morphology}

A myriad of problems are associated with farming on the precarious slopes of the Kom highlands which range from the inability for farmers to cultivate extensively, the predicament of leached soils to soil erosion. 


\section{Limited Farm Sizes}

The topographic configuration of the Kom highlands characterized by steep slopes means that extensive agricultural mechanisation is impossible. Field observations show that there is hardly any stretch of farmland that covers up to 5hectares of land. The brief sequential alteration in farming practices over space is a genuine reflection of the relief which is characterized by hilly and steep slopes. This relief attribute has thus compelled the inhabitants to small farmlands (Tasah, 2014). In this connection, agricultural productivity is bound to be low given that nature has systematically compelled the inhabitants to practice small scale agriculture. Data on income levels collected through the anthropological survey that was conducted indicate that over $60 \%$ of the sample population depend on monthly incomes of less than 75 US Dollars and based only on farming. This means that even if the natural landscape was not a major hindrance to agricultural production, mechanization which could have led to improved productivity and better livelihood might not have been possible given that farming techniques are not only outmoded but lack of capital is equally a serious constraint. Field observations also indicate that the shortage of farmland has accelerated the degradation of water catchments as farmers continue to encroach into the fragile montane ecosystem in an effort to capture more land for agriculture. This again has been another source of conflict between graziers and farmers.

\section{Leached soils}

The steep nature of slopes in the study area means that soil erosion and the downward translocation of soil mineral under the influence of gravity is accelerated. Given the topographic realities in most parts of the study area, the rate of soil development and the rate at which soil organic minerals are lost are almost the same. Most of the skeletal hilly slopes are characterized by pockets of impoverished soils which are poor in plant nutrients and hence susceptible to crop failure and various forms of mass wasting.

\section{Soil erosion}

On steep slopes, soils are washed away or blown away more easily. This means that instead of building up a thick layer of topsoil over time, the topsoil on steep slopes is eroded more quickly than new soil can form. These deposits flow down the mountain where they collect and stay on relatively more level areas. This is why the soil on the steep parts of the mountain is thinner and less fertile than on the low-lying and level parts. Data gathered through interviews and focus group discussions indicate that crop yields decline with increase in slope gradient. This, however, does not apply to certain crop types like tea, coffee, beans and solanum potatoes because they are adaptable to steep slopes. Sustainable food crops like maize, cocoyam and plantains grow only in confined locations. As slope gradient increase, the soil conditions become poor, temperatures fall and the length of the growing season is increased. This is so because soil micro-organism becomes less active under cold climatic conditions and thus the rate of decomposition is slowed down and soils become very acidic. This is the precarious conditions which compromises the livelihood of the mountain villagers.

\section{Indigenous adaptation practices to slope constraints}

Faced with a difficult and steep topography, the inhabitants of the Kom highlands who essentially depend on agriculture for a livelihood have adopted some coping mechanisms as means of overcoming the adverse farming conditions over the precipitous slopes of the study area. Some of the indigenous farming practices observed in the study area are contour ploughing, mixed cropping, use of fertilizers and shifting cultivation. 
The steep and hilly topography have forced the inhabitants to resort to contour ploughing. Given that soil erosion is greatly accelerated on steep slopes under the influence of gravity, contour ploughing seems to be an appropriate response to this phenomena and it is widely practiced in the area. This method is practiced alongside the "Ankara ridge system" which involves the gathering and burning of organic matter in ridges. Kanmegne(1996) noted that this system increases phosphorus and potash content in the soil which improves crop yield for a short period. He also noted thattherole of "ankara" in soil fertility is indeed controversial because burning accounts for the loss of more than $40 \%$ of soil nitrogen.

Mixed cropping is the most common practice in the area given that farmland is very limited. The inhabitants practice mixed cropping technique not simply as a way of maximising the use of land but as a means of guaranteeing continuous food supply throughout the year. This enables them to avoid the risk of depending on a single crop in case of crop failure and to avoid famine. This method however, brings in the problem of crop competition for nutrients. In a mixed farming system where crops are planted at much close range, competition for water, sunlight and soil minerals often results to poor yields.

Due to a rapid loss in soil nutrients resulting from leaching and soil erosion, farmers have resorted to the use of chemical fertilizers. There is unfortunately, the abusive use of such chemicals as some farmers apply more than the prescribed quantity with the hope of expecting better yields. Over application of these fertilizers is poisonous to the plant as well as pollutes the soil and underground water resources on which the population depend for their daily water needs.

Shifting cultivation also referred to as swidden cultivation, is a practice whereby the forest is cleared for limited period of cultivation after which the natural vegetation is given room to sufficiently regenerate itself before a future period of cultivation is re-introduced. There is also a tendency of cultivating many farms within a year by a single farmer. This extensification of agriculture is predicated on the hilly topography and the frequent slope failures which are in them barriers to the cultivation of one extensive farmland. Furthermore, farmers are depended on natural fertility of the soil in an environment characterized by a difficult terrain which influences the suitability of different crops. Lambi, (2001) notes that this adaptation strategy is meant to ensure that whenever nature is harsh for agricultural production on the intensely humanised hill slopes, man can still cultivate his high altitude environments when there are no compensatory agriculturally attractive lowland areas which hold promise for additional agricultural production. This practice though disappearing is still tenable in the area of study due to space availability.

\section{CONCLUSION}

The Kom highlands portray great ecological variations in terms of slope morphology and this influence agricultural patterns and productivity significantly. The hilly and mountainous terrain characterized by skeletal soils due to accelerated erosion and soil creep has favored contour and mixed cropping systems as the dominant farming practices. Even though all types of crops are cultivated in the hilly and steep slopes, field observations indicate that some specific crops such as coffee, tea, beans and solalnum potatoes thrive hilly areas because the root systems of such crops permit them to stabilize the soil and withstand adverse climatic conditions such as low temperature in the rainy seasons and very low humidity in the dry season. On gentle slopes and low lying areas, however, all crop types are grown but it is advised that for maximum productivity, agricultural technicians should educate farmers to re- 
orientate their agricultural activities to suit the various agro-ecological zones of the precarious Kom highlands.

\section{THE WAY FORWARD}

Given the enigmatic and a seemingly difficult terrain, it becomes fundamental to find out what future holds for agriculture in the Kom highlands? Can agriculture play its role as a development propellant that could contribute to the 2035 hallmark of emergence for Cameroon? Perhaps it is necessary to state here that the questions raised can be answered in the affirmative if some drastic and urgent measures are taken. It should be highlighted however that the indigenous adaptation practices such as contour ploughing, mixed cropping and mixed farming currently practiced in the study area need to be encouraged and modernised. Rather than encourage the use of chemical fertilizers whose cost is far beyond the reach of the ordinary farmer, as it is the dominant practice in the highlands, it would be advisable to train and educate the inhabitants on the use of eco-friendly and easily affordable techniques of maintaining soil fertility with the use of organic manure. It is in this light that Lambi (2001) stated that "it is time to address the land degradation problem particularly in the high altitude regions of Cameroon if highland homes for mankind today must remain a habitably productive environment for generations to come." For any land rehabilitation measure to be implemented, there is need to identify and promote community-based strategies which should integrate local indigenous knowledge into natural resource conservation within high altitude areas.

The topography of the Kom highlands provides an attractive panoramic view to the tourist. This means that instead of relying only on agriculture as the main source of livelihood, the touristic potentials of the area need to be developed by the local authorities, civil society organisations like NGOs and the local population for exploitation and diversification. In this way, income sources for the councils who are the grass root development agents will be diversified and can act as a spring board in boosting other sectors of development as well as generate employment sources that can salvage the problems linked to rural exodus. Given that the correlation between crop and slope type is very significant in the study area, it would be necessary that the agricultural technicians in the area educate farmers on the relationship between crop type and soil characteristics. This implies that a land use suitability analysis should be carried out by soil scientists, geographers and agricultural technicians to avert energy and ensure sustainability in the use of resources and better livelihood for the inhabitants.

\section{References}

Fullard, H. \& Darby, H.C. (1972). The University Atlas (Fourteenth Edition)London: George Phillip and Son

Gazel,J (1958). Carte Geologique et Geologie du Cameroun, in Atlas du Cameroun, Yaoundé: ORSTORM.

Khanchoul, K. \& Altschul, R (2008). The Relationship between Lithology and Slope Morphology in the Tucson Mountains, Arizona

Knowles, R. \& Wareing J. (1981). Economic and Social Geography Made simple Books London

Lambi, C.M. (2001). The Impact of Human Activity on Land Degradation in Some Highland Regions of Cameroon: Implications for Development In Lambi \& Eze (Ed, 2001): Environmental Issues: Problems and Prospects, Unique Printers, Bamenda

Morgan, R.P.C. (1986). Soil Erosion and Soil Conservation, Longman scientific and Technical ESSEXPP243-248

Ndenecho, E.N. (2007). Landslides and Torrent- Channel Problems of Mountain Slopes, Unique Printers, Bamenda. Neba,A. (2000). Modern Geography of the Republic of Cameroon, Bamenda, Neba Publishers. 
Nkemasong, N.\& Neba, M. (2009). Advanced Integrated Human Geography, Concepts and Techniques, AgwecamsBamenda.

Rogers, N.W. \& Salby, M.J. (1980). Mechanics of Shallow Translational Sliding During Summer Rainstorms, North Island, New Zealand Geografica Ann, No. 62- A pp11-21.

Skempton,A. W.\& Hutchinson J.N. (1969). Stability of natural slopes and embankment sections Proc 7th inter.Cont. Soil Mechanics, Fdn E. pp291-340.

Tassah,I.T.\& Lambi, C. M. (2014). Topographic Constraints and Agricultural Production in the Widekum-Menka Highlands North West Region of Cameroon, In African Journal of Social Sciences Volume 5, Number 3, Unique Printers, Bamenda, pp. 16 - 29.

Tata,E.S. Lambi, C.M,\&Mirjam De Bruijin (2013). Agro-Pastoral Movements in Bui Cameroon; What Prospects or Blueprints? in African Journal of Social Sciences Volume 4, Number 3, Unique Printers, Bamenda, pp.4-19

Whynne-Hammond (1985). Elements of human Geography, Unwin and Allen. 